\title{
Schulungs-CD TarMed
}

Inhalt:

- Ausgangslage

- Entstehungsgeschichte

- Tarifaufbau (Tarifberechnungen)

- Fallbeispiele/Abrechnungsbeispiele

- Tarifbrowser

FMH-Mitglieder können die CD zum Preis von Fr. 40.- (zuzüglich Fr. 5.50 Porto und Verpackung) beim FMH Tarifdienst bestellen. Aus administrativen Gründen können nur Bestellungen per Fax entgegengenommen werden. Lieferfrist etwa 14 Tage. Die Auslieferung erfolgt per Nachnahme. Für Nicht-Mitglieder beträgt der Preis Fr. 60.- (exkl. Porto und Verpackung).

Hinweis: Die Fallbeispiele basieren noch auf der Version TARMED 2.2. Die Fallbeispiele in der Grundversorgung werden aber durch die Änderung zu TarMed 3 nicht tangiert.

Systemvoraussetzung: Intel Pentium oder vergleichbarer Prozessor, mind. 8 MB RAM, Microsoft Windows 95/98/NT 4.0, Grafikkarte mit einer Auflösung von mindestens 800×600 und 256 Farben (empfohlen: HighColor oder TrueColor), CD-ROM Laufwerk; Internet Explorer 4.0.

sł

\section{Bestelltalon}

Name:

Vorname:

Adresse:

Unterschrift:

Anzahl CDs:

FMH Tarifdienst, Fax 0419210586 